\title{
Vasocontractile Responsiveness of Perfused Arterial Segments to Platelet-Derived Thromboxane $\mathbf{A}_{2}$
}

\author{
Tsutomu MichiBAyASHI \\ Central Clinical Laboratory, Sapporo Medical College, \\ S. 1, W. 16, Chuo-ku, Sapporo 060, Japan
}

\begin{abstract}
It remains not entirely accepted that changes in prostanoid metabolism in the blood vessel wall, as well as in whole blood, have a certain influence on vascular responsiveness to vasoactive agents. The aim of the present study is to elucidate whether platelet-derived thromboxane $\mathrm{A}_{2}\left(\mathrm{TxA}_{2}\right)$ participates in enhancement of vasoconstractile response to a pressor agent. Platelet aggregation was extraluminally induced by application of collagen to autologous platelet rich plasma (PRP), and then the PRP treated with collagen was infused into the perfusion system by means of a small infusion pump. All the prostanoids in the perfusate were assayed radioimmunologically. Infusion into the perfusion system of PRP treated with collagen, as well as that of untreated PRP, apparently caused pronounced enhancement of vasocontractile response to noradrenaline (NA), accompanied by elevations of both the level of $\mathrm{TxB}_{2}$, a stable metabolite of $\mathrm{TxA}_{2}$, and the $\mathrm{TxB}_{2} /$ prostaglandin $\mathrm{E}$ (PGE) ratio. In addition, treatment with either OKY-046 (a $\mathrm{Tx} \mathrm{A}_{2}$ synthetase inhibitor) or ketanserin (a selective $\mathrm{S}_{2}$-serotonergic antagonist) resulted in diminution of the raised vasoconstrictor response to NA induced by application of collagen to PRP.

Thus, it is possible to draw the conclusion that platelet-derived $\operatorname{TxA}_{2}$ is as potent a vasoactive substance as 5-hydroxytryptamine (5-HT) and at least in part, contributes to the enhancement of vasocontractile response to NA (NA-R) during raised platelet aggregability.
\end{abstract}

Key words: Thromboxane $\mathrm{A}_{2}$, Platelet rich plasma, Artery, Noradrenaline, Collagen

\section{Introduction}

It is well known that blood flow is regulated by neurogenic, humoral, myogenic and structural factors (Uchida \& Bohr, 1969). Total peripheral vascular resistance, related intimately to these factors, seems to be partially influenced by plasma constituents (Moretti \& Abraham, 1978 ; Rothhut, 1983) and blood corpuscle-derived vasoactive substances (GarciaSzabo, 1988; O’Brien et al., 1988). However, in many reports concerning vascular responsiveness, blood vessel contractility using a normal test solution (Tyrode's solution, Krebs' solution, etc.), containing plasma constituents and/or blood corpuscles has hardly been examined. And so, the results obtained in angiological investigations performed using normal test solutions do not always appear to reflect the genuine blood vessel contractility in the body. Even if an experiment using vascular preparations could be carried out by means of whole blood perfusion, 
it would be very difficult to evaluate whether some of the vasoactive substances originate from plasma chemical components, blood cells or blood vessels. It remains, moreover, not fully known as to whether alterations in prostanoid metabolism in the vascular beds have an influence on blood vessel contractility (Cappuccio, 1986 ; Nowak \& FitzGerald, 1987).

Thus, the present study was undertaken using perfused arterial segments with the aim of evaluating whether changes in the prostanoid level in the blood vessel wall participate in vascular responsiveness to vasoactive substances when infusing PRP with or without collagen into the perfusion system.

\section{Materials and Methods}

Male Japanese white rabbits weighing 2.5 to $3.0 \mathrm{~kg}$ were anesthetized with sodium pentobarbital (30 to $60 \mathrm{mg} / \mathrm{kg}$ ). Following injection of heparin $(1,000 \mathrm{U} / \mathrm{kg}$, i.v.) into the marginal ear vein, approximately $80 \mathrm{ml}$ of whole blood was obtained from the femoral artery with needle (21 gauge) cannulation and collected into a beaker containing sodium citrate (3.8\% $\mathrm{w} / \mathrm{v}, 1$ part +9 parts of blood). $\quad \mathrm{PRP}$ (platelet count $40.6 \times 10^{4} \pm 14.1 \times 10^{4} / \mathrm{mm}^{3}$, mean \pm S.D., $\mathrm{n}=$ 4), obtained by centrifuging the whole blood at $1,000 \mathrm{rpm}$ for $10 \mathrm{~min}$ at room temperature, was used within $15 \mathrm{hrs}$ following blood collection. Following this step, the arterial segment was dissected from the proximal portion of the central artery of the rabbit ear. This segment, approximately $2.7 \mathrm{~cm}$ long, was separately cannulated at the proximal and distal ends with polyethylene tubing, and it was installed in a nearly $5 \mathrm{ml}$ organ bath apparatus in a horizontal plane according to a slight modification of the procedure of De La Lande (De La Lande et al., 1966). This preparation was then perfused with a modified Krebs solution by means of a roller pump delivering a constant flow of $3 \mathrm{ml} / \mathrm{min}$ (Michibayashi, 1984). The modified Krebs solu-

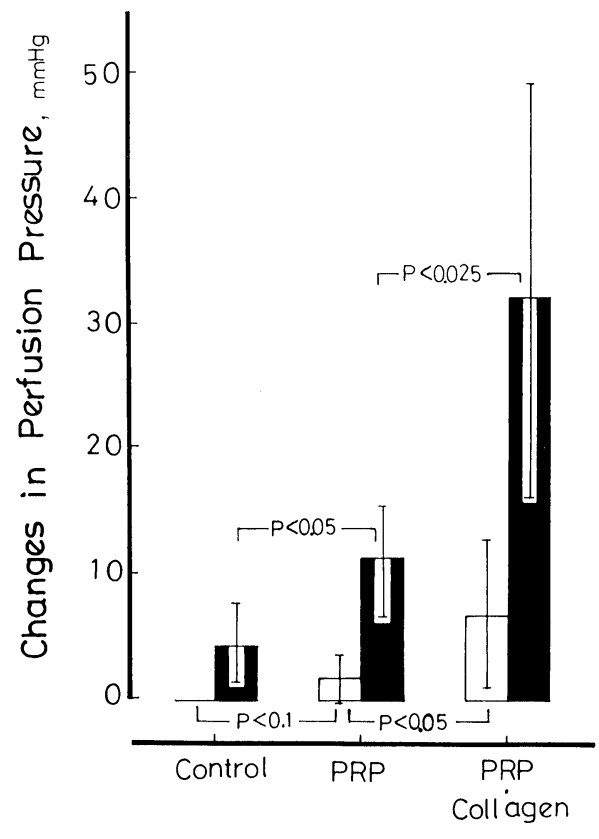

Fig. 1. Changes in perfusion pressure.

Control : perfusion of a modified normal Krebs solution, PRP : perfusion during infusion of collagen-untreated PRP, $\mathrm{PRP} \cdot$ Collagen : perfusion during infusion of collagen-treated PRP. Changes in basal perfusion pressure $(\square, n=8)$ and in vasocontractile response to noradrenaline $(\boldsymbol{\square}, \mathrm{n}=7)$ were represented in this figure. Each value and vertical bar indicate the means and tsandard deviations of the mean, respectively. Noradremaline, 1.25 to $5.0 \mathrm{ng} / 0.1 \mathrm{ml}$ of a modified normal Krebs solution, was injected as a single bolus. 
tion used in the present study had the following composition (mM): $\mathrm{Na}^{+}, 137.0 ; \mathrm{K}^{+}, 5.9 ; \mathrm{Ca}^{++}$, $1.8 ; \mathrm{Mg}^{++}, 1.2 ; \mathrm{Cl}^{-}, 123.9 ; \mathrm{HCO}_{3}^{-}, 25.0$; glucose, 8.3 and sucrose, 20.0. This solution ( $\mathrm{pH} 7.4$, $37^{\circ} \mathrm{C}$ ) was equilibrated with a gas mixture of $95 \% \mathrm{O}_{2}+5 \% \mathrm{CO}_{2}$, and then 20 to $40 \mu \mathrm{g} / \mathrm{ml}$ of ascorbic acid was added. A suitable concentration of $0.1 \mathrm{ml}$ of NA, freshly prepared in normal Krebs solution, was injected as a bolus into a rubber tube connected to the central arterial cannula, followed by perfusion pressure change $(\mathrm{mmHg})$. The perfusates were collected for 2 min $2 \mathrm{hr}$ after beginning of perfusion of a modified normal Krebs solution alone (the control sample), 30 min after infusion of PRP (the PRP sample), and 8 min after infusion of PRP treated with collagen (the PRP•collagen sample). Each sample of perfusate from every experiment was stored at $-20^{\circ} \mathrm{C}$ immediately following collection. Extraction of prostanoids in the perfusate was carried out within one week after perfusate collection, as reported previously (Michibayashi, 1989), followed by further purification handling according to the method of Inagawa (Inagawa et al., 1972) to eliminate remaining lipids. And then, the concentrations of $\mathrm{PGE}\left(\mathrm{PGE}_{1}+\mathrm{PGE}_{2}\right), \mathrm{TxB}_{2}$ and 6 -keto- $\mathrm{PGF}_{1 \alpha}$ in the perfusate were measured by radioimmunoassay. In the experiment examining the effect of PRP with or without collagen on NA$\mathrm{R}$, autologous PRP was infused into the perfusion system at the rate of $3 \mathrm{ml} / \mathrm{hr}$ with a Micro

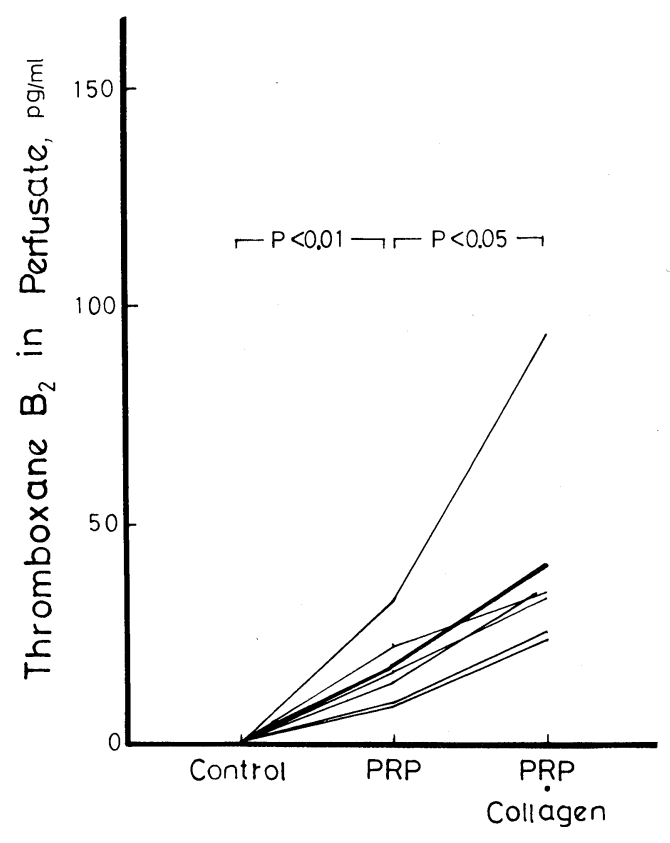

Fig. 2A. Changes in $\mathrm{TxB}_{2}$ level in perfusate. Control : perfusion of a modified normal Krebs solution, PRP: perfusion during infusion of collagen-untreated $\mathrm{PRP}, \mathrm{PRP} \cdot$ Collagen : perfusion during infusion of collagen-treated PRP. Thick line indicates mean value $(n=6)$.

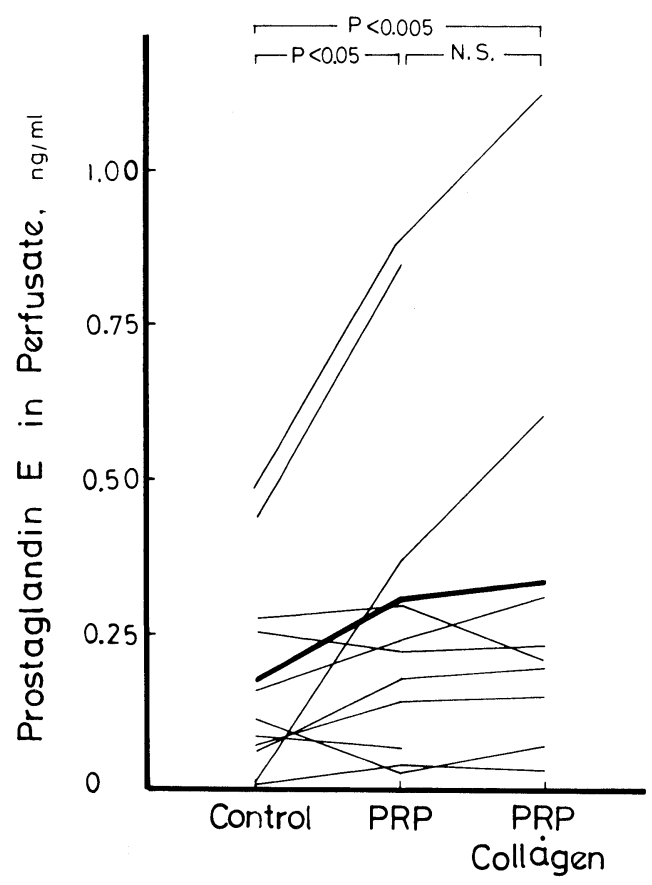

Fig. 2B. Changes in PGE level in perfusate. Control: perfusion of a modified normal Krebs solution, PRP: perfusion during infusion of collagen-untreated $\mathrm{PRP}, \mathrm{PRP} \cdot$ Collagen : perfusion during infusion of collagen-treated PRP. Thick line indicates mean value $(n=$ 11). 


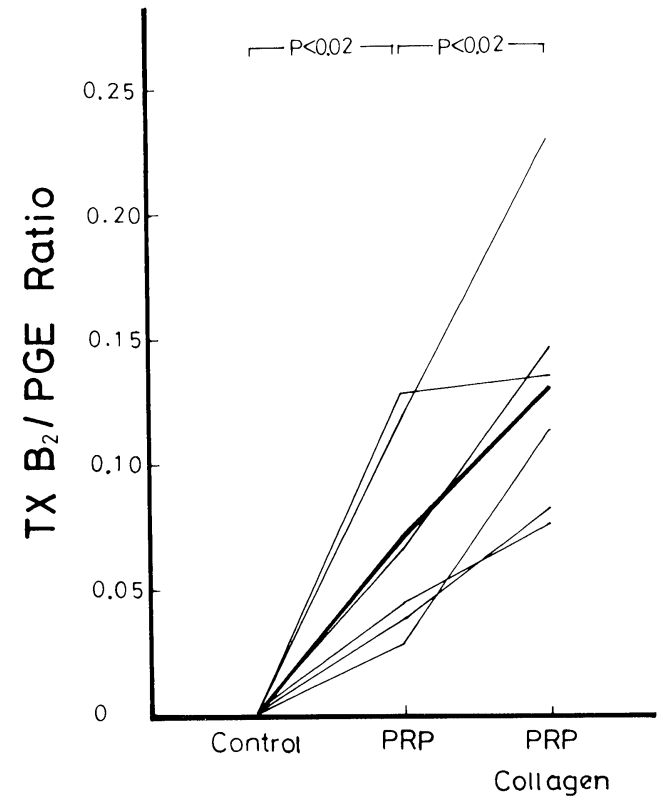

Fig. 3. Changes in $\mathrm{TxB}_{2} / \mathrm{PGE}$ ratio in perfusate. Control : perfusion of a modified normal Krebs solution, PRP: perfusion during infusion of collagen-untreated PRP, $\mathrm{PRP} \cdot$ Collagen: perfusion during infusion of collagen-treated PRP. Thick line indicates mean value $(n=6)$.

Infusion Pump (SP-5, Nipro, Japan). Under this condition, the flow rate was increased about one sixtieth of that during perfusion of the modified normal Krebs solution alone (about $0.05 \mathrm{ml} /$ min) more than that of preinfusion state, while this infusion rate of normal test solution without PRP did not elicit any elevation of basal perfusion pressure. Platelet aggregation was induced by the addition of collagen $(0.4$ to $4.0 \mu \mathrm{g} / \mathrm{ml})$ into the syringe containing PRP. This step was followed by the observation of NA-R represented on the smoked drum as perfusion pressure change, and then, by the perfusate sampling. Furthermore, OKY-046 (a thromboxane synthetase inhibitor, 0.1 to $1.0 \mu \mathrm{g} / \mathrm{ml}$ ) was applied to autologous PRP for the purpose of inhibiting $\mathrm{TxA}_{2}$ biosynthesis in platelets. Also, ketanserin tartrate (a selective $5-\mathrm{HT}_{2}$ receptor antagonist, 45 to $450 \mathrm{ng} / \mathrm{ml}$ ) was applied to the perfusion system in order to suppress the effect of platelet - derived 5-HT on the blood vessel contractility.

The drugs used were sodium citrate (Midorijyuzi) ; collagen (Worthington Biochemical Co.) ; noradrenaline (SIGMA); authentic prostanoids of $\mathrm{PGE}_{1}, \mathrm{TxB}_{2}$ and 6 -keto- $\mathrm{PGF}_{1 \alpha}(\mathrm{Ono}$ Pharmaceutical Co.) ; ${ }^{3} \mathrm{H}$-labelled prostanoids of ${ }^{3} \mathrm{H}-\mathrm{PGB}_{1},{ }^{3} \mathrm{H}-\mathrm{TxB}_{2}$ and ${ }^{3} \mathrm{H}-6$-keto- $\mathrm{PGF}_{1 \alpha}$ (New England Nuclear); antisera for PGB (Ono Pharmaceutical Co.), TxB 2 (bio yeda) and 6keto- $\mathrm{PGF}_{1 \alpha}$ (bio yeda); indomethacin (SIGMA); OKY-046 (Ono pharmaceutical Co.) and ketanserin tartrate (Kyowahakko).

Results obtained in the present study were expressed as mean \pm S.D.. All data were analyzed using the $\mathrm{F}$-test and a difference of $\mathrm{P}<0.05$ was considered to be significant.

\section{Results}

\section{Blood vessel contractility and platelet aggregation}

At first, the effect of PRP on the basal perfusion fressure was examined. During infusion of untreated PRP, the basal perfusion pressure was hardly altered, though it was raised a little 


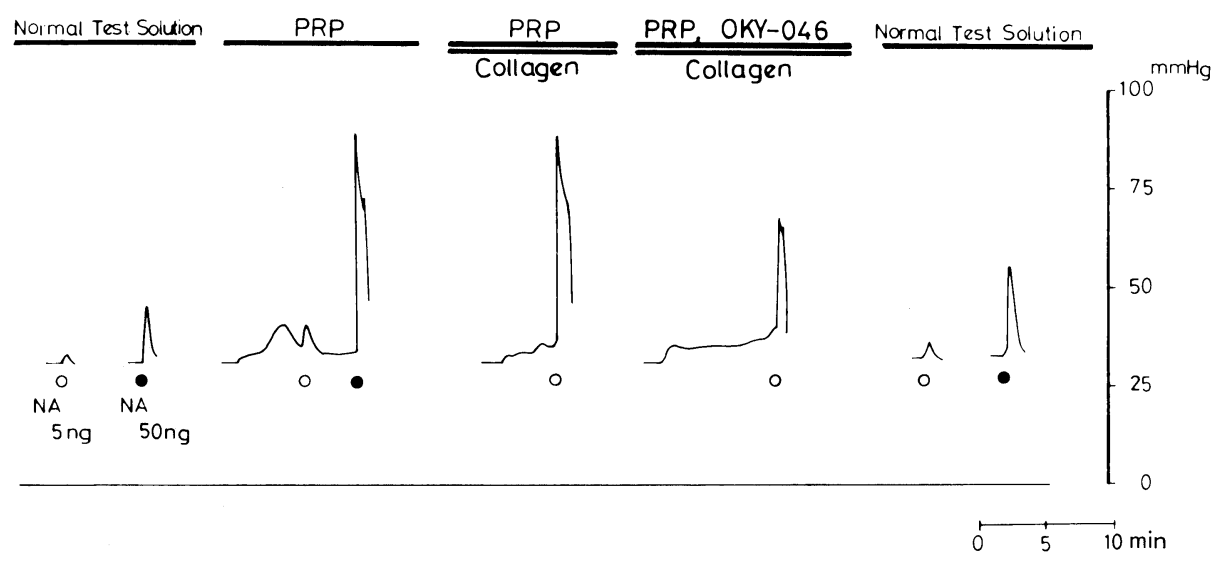

Fig. 4. Inhibitory effect of $\mathrm{OKY}-046$ on the enhanced vasoconstrictor response to noradrenaline during infusion of collagen-treated PRP.

Three experiments were carried out. Of these experiments, a typical case undertaken in the presence of OKY-046, $100 \mathrm{ng} / \mathrm{ml}$, is shown in this figure.

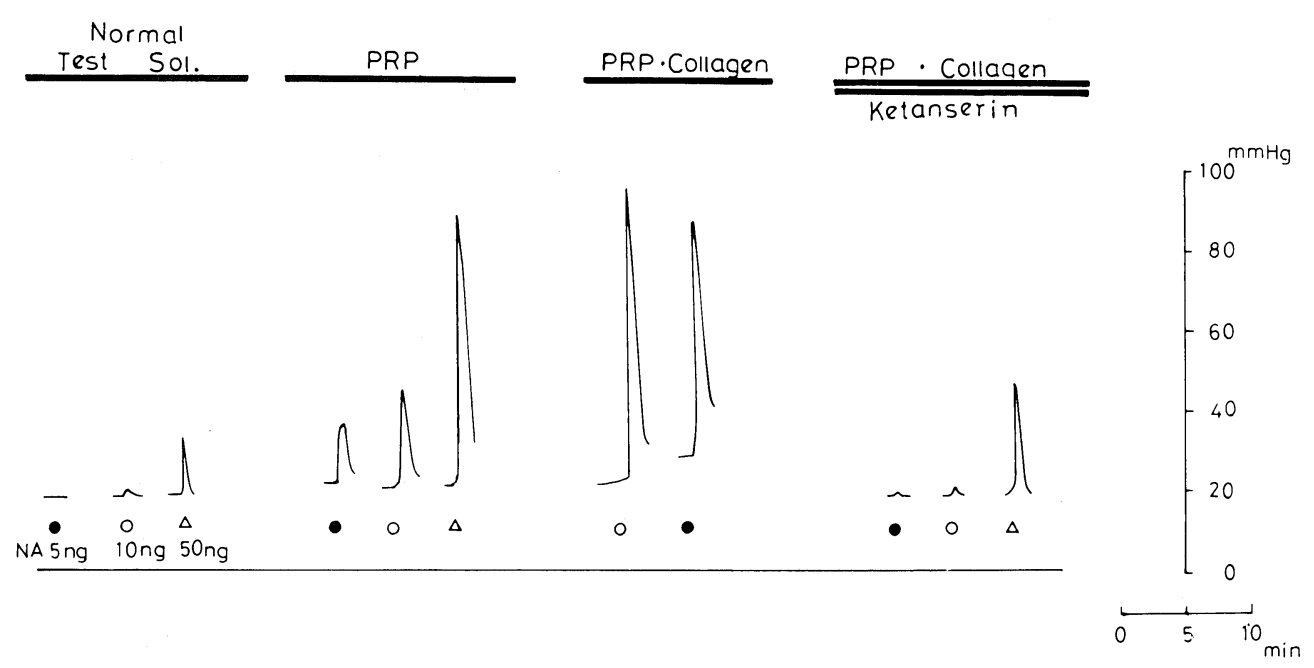

Fig. 5. Inhibitory effect of ketanserin on the enhanced vasocontractile renponse to noradrenaline during infusion of collagen-treated PRP.

Four experiments were carried out. Of these experiments, a typical case undertaken in the presence of katanserin, $45 \mathrm{ng} / \mathrm{ml}$, is shown in this figure.

in a few preparations, whereas NA-R was significantly augmented $(11.4 \pm 4.4 \mathrm{mmHg}, \mathrm{n}=7, \mathrm{P}<$ $0.05)$ in comparison with the control response $(4.6 \pm 3.1 \mathrm{mmHg}, \mathrm{n}=7$, Fig. 1$)$. Subsequently, the effect of collagen-induced platelet aggregation on NA-R was examined. The basal perfusion pressure was transiently unstable, after which it was gradually stabilized several minutes after collagen application. Changes in the basal perfusion pressure during infusion with collagen $(6.8 \pm 6.1 \mathrm{mmHg}, \mathrm{n}=8, \mathrm{P}<0.05)$ was shown to be significantly more increased than those of PRP without collagen $(1.8 \pm 2.0 \mathrm{mmHg}, \mathrm{n}=8)$. Following this, NA-R was examined. As can be seen in Fig. 1, 1.25 to $5.0 \mathrm{ng}$ of NA injected as a bolus resulted in a significantly raised response 
$(32.1 \pm 16.9 \mathrm{mmHg}, \mathrm{n}=7, \mathrm{P}<0.025)$ in comparison with that during infusion of untreated PRP.

\section{Changes in prostanoid level in perfusates}

As can be seen in Fig. $2 \mathrm{~A}$, no $\mathrm{TxB}_{2}$ level was detected in any perfusates during perfusion of a modified normal Krebs solution, whereas this level was elevated to assayable values in all the preparations during infusion of PRP. Both levels of $\mathrm{TxB}_{2}$ during infusion of PRP alone $(16.8 \pm 8.2 \mathrm{pg} / \mathrm{ml}, \mathrm{n}=6, \mathrm{P}<0.01)$ and of PRP treated with collagen $(40.3 \pm 23.9 \mathrm{pg} / \mathrm{ml}, \mathrm{n}=6, \mathrm{P}<$ $0.05)$ were significantly higher than the control (undetectable amount, $n=6$ ). Furthermore, there was a significant $(\mathrm{P}<0.05)$ difference between both levels of $\mathrm{TxB}_{2}$ during infusions of PRP with and without collagen. Also, with regard to PGE (Fig. 2B), both levels of PGE during infusion of PRP alone $(0.295 \pm 0.284 \mathrm{ng} / \mathrm{ml}, \mathrm{n}=11, \mathrm{P}<0.05)$ and of PRP treated with collagen $(0.320 \pm 0.324 \mathrm{ng} / \mathrm{ml}, \mathrm{n}=9, \mathrm{P}<0.05)$ were significantly higher than the control $(0.172 \pm 0.156 \mathrm{ng} /$ $\mathrm{ml}, \mathrm{n}=11$ ), although the PGE level deviated greatly and there was no significant difference between either level of PGE during infusions of PRP with and without collagen. As regards 6-keto-PGF ${ }_{1 \alpha}$, there was no significant difference between levels of 6 -keto-PGF $1 \alpha$ in any perfusate (normal Krebs solution: $0.166 \pm 0.161 \mathrm{ng} / \mathrm{ml}, \mathrm{n}=8, P R P$ alone : $0.172 \pm 0.135 \mathrm{ng} / \mathrm{ml}$, $\mathrm{n}=6$, and PRP treated with collagen : $0.170 \pm 0.190 \mathrm{ng} / \mathrm{ml}, \mathrm{n}=6$ ). Likewise, alterations in the $\mathrm{TxB}_{2} / \mathrm{PGE}$ ratio in the perfusates were evaluated (Fig. 3). Consequently, it was shown that the $\mathrm{TxB}_{2} / \mathrm{PGE}$ ratio during infusion of untreated PRP $(0.07 \pm 0.04, \mathrm{n}=6, \mathrm{P}<0.02)$ was significantly higher than the control (approximately zero, $n=6$ ) and as expected, was significantly lower than that of PRP treated with collagen $(0.130 \pm 0.051, \mathrm{n}=6, \mathrm{P}<0.02)$.

\section{Effect of the thromboxane synthetase inhibitor on vasoconstrictor response}

Firstly, OKY-046 (0.1 to $1.0 \mu \mathrm{g} / \mathrm{ml})$ was added to the syringe containing PRP in order to depress $\mathrm{TxA}_{2}$ synthetase activity. About $30 \mathrm{~min}$ after $\mathrm{OKY}-046$ treatment, platelet aggregation was elicited by application of collagen $(0.4$ to $4.0 \mu \mathrm{g} / \mathrm{ml})$ to the syringe. Subsequently, this PRP was infused into the perfusion system using a MICRO INFUSION PUMP, afterwhich the comparison between the responses to NA in the absence and presence of OKY-046 was made. In consequence, it was clarified that collagen - induced enhancement of NA-R was diminished by OKY-046 (Fig. 4).

\section{Effect of the 5-hydroxytryptamine receptor antagonist on vasoconstrictor response}

Platelet aggregation is well known to cause the release of several vasoactive agents from platelets. Among the vasoactive agents originating from platelets, $5-\mathrm{HT}$ is as potent a vasoactive substance as $\mathrm{TxA}_{2}$. And so, finally, the effect of ketanserin on NA-R during infusion of PRP treated collagen was examined. As can be seen in Fig. 5, ketanserin, $45 \mathrm{ng} /$ $\mathrm{ml}$, was firstly infused into the perfusion system, then $30 \mathrm{~min}$ later $5 \mathrm{ng}$ of NA was applied as a bolus. Consequently, ketanserin was revealed to abolish the enhancement of NA-R during infusion of PRP with collagen.

\section{Discussion}

As is well known, many clinical signs of cardiovascular disorders are clearly related to 
changes in blood vessel contractility and/or blood flow. Recently, it has been demonstrated that alterations in prostanoid metabolism in vascular beds have an influence on the vasocontractile responsiveness to vasoactive agents (Michibayashi, 1984 ; Nowak \& FitzGerald, 1987 ; Neri Serneri et al., 1990). It now seems that prostanoid biosynthesis of the vascular beds in the body appears to be more accurately reflected in results obtained by perfusing normal test solution containing blood chemical components and/or blood cells rather than by normal test solution alone. However, reports concerning the relationship between prostanoid metabolism in blood vessel walls and vascular responsiveness in the presence of plasma constituents and blood cells have been fewer (Moretti \& Abraham, 1978 ; Smith et al., 1980). And so, in the present study, the interaction of blood vessel contractility with platelet aggregation was evaluated by infusing PRP into the perfusion system. It was impossible to detect $\mathrm{TxB}_{2}$ in the perfusate collected during perfusion of normal test solution, although it became detectable following infusion of PRP in all preparations (Fig. 2A). This result may suggest that $\mathrm{TxA}_{2}$ mainly originates from PRP, primarily platelets. Also, PRP infusion-related enhancement of NA-R was accompanied by a significant elevation of the $\mathrm{TxB}_{2}$ level (Fig. $2 \mathrm{~A}$ ) and the $\mathrm{TxB}_{2} /$ $\mathrm{PGE}$ ratio (Fig. 3). As regards vasodilator prostanoids, the PGE level was significantly elevated during infusion of PRP with and without collagen in comparison with that of control, though application of collagen to PRP did not cause any significant elevation of the PGE level (Fig. 2B). In addition, PRP introduction did not elicit any significant difference in the 6-keto$\mathrm{PGF}_{1 \alpha}$ level in any preparation. Therefore, $\mathrm{TxA}_{2}$ appears to be, at least partially, involved in PRP-induced augmentation of NA-R. This estimation seems to be supported by the fact that pretreatment with either OKY-046 (Fig. 4) or indomethacin (Michibayashi, 1991), applied to PRP with the aim of suppressing prostanoid biosynthesis, attenuates the enhancement of NA$\mathrm{R}$ following application of collagen to PRP. Moreover, since ketanserin almost entirely abolishes NA-R during collagen-induced platelet aggregation (Fig. 5), it is speculated that $\mathrm{TxA}_{2}$ may have an accelerating action on the augmented NA-R with the infusion of collagentreated PRP. As regards platelet-derived 5-HT, in order to understand the powerful action of ketanserin, it appears necessary to take into consideration that, in addition to a selective $5-\mathrm{HT}_{2}$ receptor antagonistic action, this blocker possesses a moderate $\alpha_{1}$-adrenoreceptor antagosistic effect (Amstein et al., 1988 ; Ramage, 1988). Thus, it seems possible to propose that 5-HT, as well as $\mathrm{TxA}_{2}$, is involved in augmentation of NA-R during infusion of collagen-treated PRP.

As is generally accepted, ischemic heart disease, cerebral thrombosis, essential hypertension, diabetes mellitus and the classical cardiovascular disorders are readily accompanied by platelet aggregation and their clinical signs are greatly affected by an interaction of vascular responsiveness with platelet aggregability, the main subject in the present study. Recently, in addition to prostanoid and 5-HT, many investigators have presented a great amount of data concerning endothelium-derived relaxing factor (Ignarro et al., 1987a ; Ignarro et al., 1987b), endothelin (Yanagisawa et al., 1988 ; Salom et al., 1991), platelet-derived growth factor (Araki et al., 1990) and leukotriene (Wittman et al., 1987 ; Hillyard et al., 1991). Therefore, it may be necessary, in order to elucidate their physiological and/or pathophysiological roles in the body, to study these vasoactive substances by using blood vessel preparations, blood cells and plasma constituents in the future. 


\section{Acknowledgement}

I wish to express my appreciation to the Research Institute, Ono Pharmaceutical Co. Ltd., Japan, for kindly supplying authentic PGs and antiserum. Also, I am grateful to Kyowahakkokōgyo Co. Ltd., Japan, for the kind supply of ketanserin.

\section{References}

Amstein, R., Fetkovska, N., Pletscher, A. and Bühler, F.R. (1988). Platelet deactivation by $5-\mathrm{HT}_{2}-$ receptor blockade parallels the antihypertensive response to ketanserin. J. Hypertension 7 : 255-260.

Araki, S., Kawahara, Y., Kariya, K., Sunako, M., Tsuda, T., Fukuzaki, H. and Yoshimi, T. (1990). Stimulation of platelet-derived growth factor-induced DNA synthesis by angiotensin II in rabbit vascular smooth muscle cells. Biochem. Biophys. Res. Commun. 168: 350-357.

Cappuccio, F.P., Sagnella, G.A., Leathard, H.L., Markandu, N.D. and MacGregor, G.A. (1986). Evidence using human arterial tissue for a circulating vascular sensitizing agent in essential hypertension. J. Clin. Endocrinol. Metab. 63 : 463-467.

De La Lande, I.S., Cannell, V.A. and Waterson, J.G. (1966). The interaction of serotonin and noradrenaline on the perfused artery. Br. J. Pharmacol. Chemother. 28 : 255-272.

Garcia-Szabo, R., Johnson, A. and Malik, A.B. (1988). Thromboxane increases pulmonary vascular resistance and transvascular fluid and protein exchange after pulmonary microembolism. Prostaglandins 35 : 707-721.

Hillyard, R., Anderson, J. and Raj, J.U. (1991). Segmental vascular resistance in isolated perfused rat lungs. Influence of vasomotor tone and cyclooxygenase and lipoxygenase inhibition. Circ. Res. 68: 1020-1026.

Ignarro, L.J., Byrns, R.E., Buga, G.M. and Wood, K.S. (1987a). Endothelium-derived relaxing factor from pulmonary artery and vein possesses pharmachologic and chemical properties identical to those of nitric oxide radical. Circ. Res. 61: 866-879.

Ignarro, L.J., Buga, G.M., Wood, K.S., Byrns, R.E. and Chaudhuri, G. (1987b). Endothelium-derived relaxing factor produced and released from artery and vein is nitric oxide. Proc. Nat. Acad. Sci. 84 : 9265-9269.

Inagawa, T., Ohki, S., Sawada, M. and Hirata, F. (1972). Studies on extraction, separation and estimation of prostaglandins by radioimmunoassay. Yakugaku Zasshi 92: 1187-1194, (in Japanese).

Michibayashi, T. (1984). Relationship between endogenous prostaglandin E and the vasoconstrictor response to noradrenaline in a perfused arterial segment. Jap. J. Pharmacol. 35 : 259-264.

Michibayashi, T. (1989). Prostaglandins released from the isolated perfused arterial segment and vasocontractile response - Influence of plasma constituents and platelets - Jap. J. Smooth Muscle Res. 25: 31-38, (in Japanese).

Michibayashi, T. (1991). Immunological assay of substances originating from blood and vascular beds and its issue in future. Jap. J. Clin. Pathol. 39: 173-178, (in Japanese).

Moretti, R.L. and Abraham, S. (1978). Stimulation microsomal prostaglandin synthesis by a blood plasma constituent which augments autoregulation and maintenance of vascular tone in isolated rabbit hearts. Circ. Res. 42: 317-323.

Neri Serneri, G.G., Castellani, S., Scarti, L., Trotta, F., Chen, J.L., Carnovali, M., Poggesi, L. and Masotti, G. (1990). Repeated sympathetic stimuli elicit the decline and disappearence of prostaglandin modulation and an increase of vascular resistance in humans. Circ. Res. 67 : 580-588.

Nowak, J. and FitzGerald, G.A. (1987). In vivo formation of prostacyclin and thromboxane $\mathrm{A}_{2}$ at the 
site of platelet-vascular interaction in humans. Adv. Prostaglandin Thromboxane Leukotriene Res. 17A : 208-211.

O’Brien, W.F., Knuppel, R.A., Saba, H.I., Benoit, R. and Bruce, A. (1988). Serum prostacylin binding and half-life in the umbilical circulation. Prostaglandins. $35: 185-190$.

Ramage, A.G. (1988). Are drugs that act both on serotonin receptors and $\alpha_{1}$-adrenoreceptors more potent hypotensive agents than those that act only on $\alpha_{1}$-adrenoreceptors? J. Cardiovasc. Pharmacol. 11 (suppl 1) : S30-S34.

Rothhut, B., Russo-Marie, F., Wood, J., DiRosa, M. and Flower, R.J. (1983). Further characterization of the glucocorticoid-induced anti-phospholipase protein "renocortin". Biochem. Biophys. Res. Commun. 117 : 878-884.

Salom, M.G., Lahera, V. and Romero, J.C. (1991). Role of prostaglandins and endothelium-derived relaxing factor on the renal response to acetylcholine. Am. J. Physiol. 260: F145-F149.

Smith, J.B., Araki, H. and Lefer, A.M. (1980). Thromboxane $A_{2}$, prostacyclin and aspirin : Effects on vascular tone and platelet aggregation. Circulation. 62 (suppl V): V-19-V-25.

Uchida, E. and Bohr, D.F. (1969). Myogenic tone in isolated perfused resistance vessels from rats. Am. J. Physiol. 216 : 1343-1350.

Wittman, G., Peskar, B.M., Edelmann, M., Müller, K.M., Simmet, Th. and Peskar, B.A. (1987). Formation of cysteinyl-containing leukotrienes by human arterial tissues. Prostaglandins. $33: 591-598$.

Yanagisawa, M., Kurihara, H., Kimura, S., Tomobe, Y., Kobayashi, M., Mitsui, Y., Yazaki, Y., Goto, K. and Masaki, T. (1988). A novel potent vasoconstrictor peptide produced by vascular endothelial cells. Nature. 332: 411-415. 